\title{
A Design Approach to Zoological Exhibits: The Zoo as Theater
}

\author{
Kenneth J. Polakowski \\ University of Michigan, School of Natural Resources, Ann Arbor
}

\begin{abstract}
The purpose of this paper is to present a unique exhibit design approach that is capable of contributing to the conservation of endangered primates. The approach recognizes the need to link the animal's plight to its environmental context, including its natural habitat and the cultural and economic influences of man. The basis of the design recommendations was generated by an analysis of the design dilemmas that confront the exhibit design team, especially the contradictions that exist between the mind and the eye or the message (conservation/education) and the media (exhibit area). The design approach stresses the importance of creating perceptual illusions of the animal's habitat while recognizing the primates' physical, psychological, and social needs.

The paper introduces the "zoo as theater" as a means to understand the educational and entertainment opportunities that can be developed in our nation's zoos. This unique outlook is presented to inspire bold thinking and a shift in attitude in the search for imaginative and memorable exhibits that will encourage the visitor "to think globally and act locally" about the conservation of endangered species.

The design approach focuses on the reality of illusions and their importance in the zoo visitor's total experience: from the anticipation of the visit, to the actual animal encounters at the zoo, to remembering the visions of the trip. It adopts some basic theories of optical illusions translating them into design guidelines that help 1) simulate the animal's natural habitat, 2) produce an atmosphere similar to the animal's environment, 3) focus on the outstanding physical features of the animal, and 4) emphasize the ecological relationships between animals, habitat and man.
\end{abstract}

Key words: zoo design, primate exhibits, perceptual illusions, theater design, conservation

\section{INTRODUCTION}

Realizing the tremendous influence that the zoo exhibit design team may have on the conservation of endangered plant and animal species, how should they approach the design of a primate exhibit? Is it possible to extend the passive recreational

Received for publication February 14, 1987; accepted August 2, 1987.

Address reprint requests to Kenneth J. Polakowski, 1548 Dana Building, School of Natural Resources, Ann Arbor, MI 48109. 
experience of the zoo visitor into actions that will contribute to the preservation and protection of primates and their habitat? How can the primate exhibit design team overcome the inherent institutional constraints, development goal contradictions, and perceptual dilemmas to create a memorable and pleasurable experience for the zoo visitor?

A positive response to these questions is dependent on the approach the design team employs and the attitude they adopt at the outset of the design process. They should think of exhibit design as an opportunity to creating an educational experience that can awaken the visitor to the exhibit message and encourage the visitors to ponder their role in resolving the environmental conflicts that endanger the existence of primates throughout the world. The design approach must be flexible, innovative, opportunistic, and rational. It should be capable of encouraging the zoo visitor "to think globally and act locally" about the plight of the wondrous primates that they are viewing.

\section{THE EXHIBIT MESSAGE}

The primate exhibit is a "natural" attraction for the zoo visitor because of man's close association with the mammalian Order Primates. It provides outstanding educational opportunities and the chance to apply the results of research by field biologists (ie, van Lawick-Goodall [1967], Fossey [1983], Schaller [1963] regarding the ecology and behavior of primates. A well conceived and well executed exhibit that utilizes such research data by attempting to replicate the primates' natural habitat is an interesting and entertaining place and provides the opportunity to learn more about the origins, evolution, and behavior of both nonhuman primates and ourselves.

The primate exhibit offers the unique opportunity for conveying the linkage between animals and their habitat. Primates are a conspicuous group of animals in a tropical forest and they are excellent indicators of a healthy environment. A crisis exists because the current and rampant destruction of the forest is causing a decrease in the primate population. Ninety percent of all primates live in tropical forests, onethird of the primate species are threatened or endangered and nearly one-seventh face extinction [World Wildlife Fund, 1986]. The exhibit and the interpretative signs should express a strong message: In order to save the many endangered primates, we must save the forests. Exhibits should stress the importance of habitat conservation and encourage the visitor to support international efforts to establish new parks and reserves. They have the potential to direct and focus attention on the conservation of the most threatened environments. (Madagascar is considered by many biologists to be of the highest conservation priority because it has the greatest number of unique flora and fauna species in the greatest danger of extinction.)

The exhibit should attempt to link habitat destruction with the impact of global economics on management practices of local landowners. The practice of clearing native forests for the cultivation of cash export crops is influenced by world markets. (An example is the production of vanilla in Madagascar. This land, once occupied by indigenous flora, has been devastated by the world's demand craze for cola soft drinks, vanilla being a major ingredient in cola drinks.) The exhibit should contribute to the modification of economic policies that put development ahead of conservation. It should present the realities of slash and burn agriculture, overgrazing, uncontrolled firewood gathering, soil erosion, and the population explosion. The conservation 
message must also portray the reality of local conditions. It is not unusual that the city dweller in a developing country, surrounded by the wild countryside, will only encounter his nation's native flora and fauna in the local zoo or botanical garden. Meanwhile, the rural peasant is contributing to this crisis, by hunting the endangered primates and destroying its habitat.

The exhibit can contribute to a change in the zoo visitor's attitudes about supporting conservation efforts at home and abroad, especially the establishment of nature reserves. Reserves, aside from being fascinating and providing a place for scientists to work, offer the opportunity to develop in the local residents an awareness and admiration of the native plants and animals. This new awakening can instill respect, and this respect can encourage further understanding that could eventually make local residents advocates for the protection and preservation of natural resources.

\section{EXHIBIT DESIGN DILEMMAS}

It is a big leap from understanding the conservation message to the design of an exhibit that can adequately convey that message. The new conservation role of the zoo requires new design attitudes, new processes, and new techniques to achieve the conservation objectives [Jones, 1985]. It also requires the use of new concepts to complement current design philosophies, further discussion and research, and, finally, an open and inquisitive mind to investigate the current exhibit design dilemmas.

The primate exhibit design approach, in addition to satisfying the animals' physical, psychological, and social needs, should recognize that ultimately the exhibit attempts to present an illusion of the wild. It should recognize that perceptual illusions are a means to awaken the visitors, excite them to discover the realities of animals, plants, and man, and encourage them to take action toward the conservation of the world's natural resources. An approach that understands and recognizes the significance of illusions in design must also recognize the inherent perceptual dilemmas that confront the designer.

The dilemma of exhibiting "wild" primates in an "artificial and protected" environment requires the creation of perceptual deceptions in the visitor's mind. This problem can be partially solved by the exhibit designer adopting an attitude that "perceiving" exhibited primates in a "deceiving" way is both positive and natural.

There is a dilemma in presenting the reality of survival in nature to the visitor who has come to the zoo for a good time, ready to have fun and daydream about wild fantasy illusions. Unfortunately, the visitor is often presented an illusion of the captive primate as docile, approachable, and friendly; very different from their counterparts in the wild.

Another dilemma is creating an exhibit that expresses the multiple roles of zoological institutions. Contradictions between recreation, education, conservation, and research policies are very difficult to alleviate and are often disastrous in the development of an excellent exhibit. Exhibit design must admit to the real priorities of the development project and not attempt to present administrative or managerial illusions that reduce the exhibit's effectiveness. Not every exhibit can provoke a conservation response and be entertaining and educational.

The resolution of these design dilemmas in a manner that respects primates and excites visitors requires an innovative design attitude that can be influenced by considering the metaphor of the "zoo as theater". This approach is presented to 


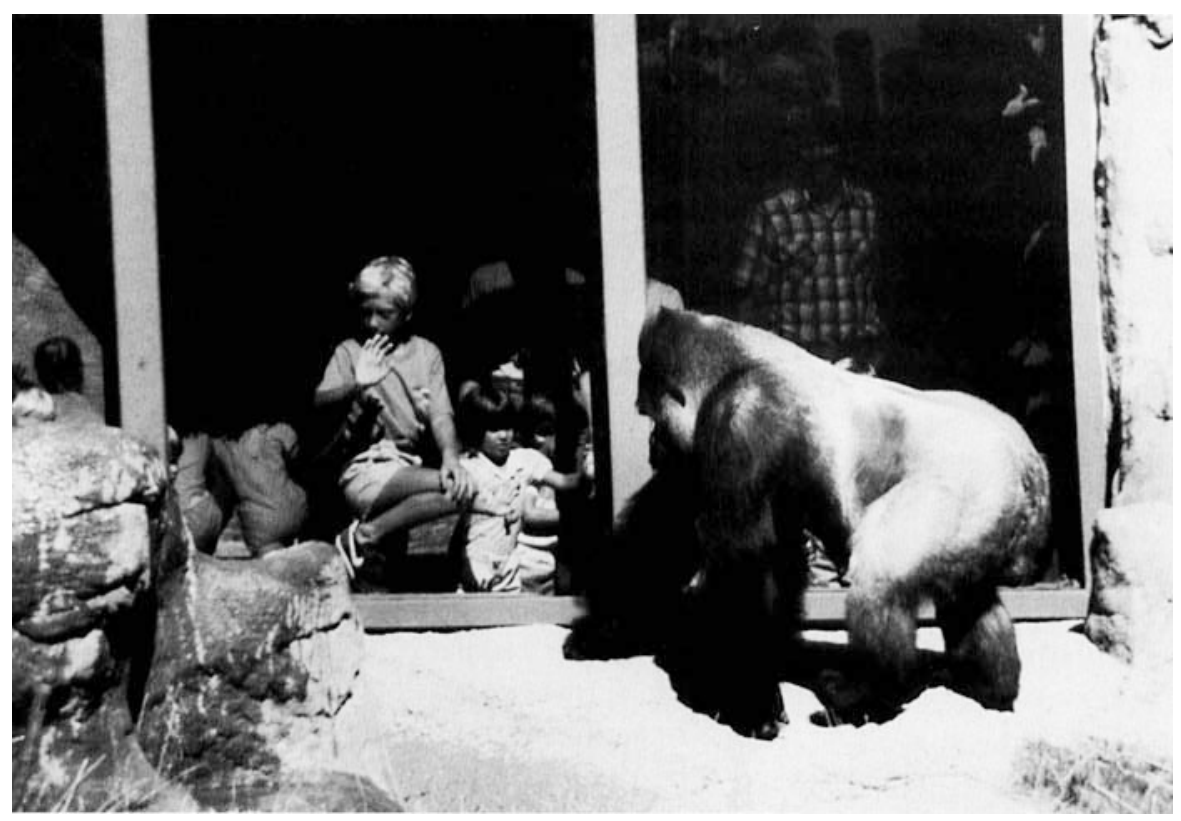

Fig. 1. The zoo as theater, both share the concept of a stage; performers and audience focusing on education through entertainment at the gorilla encounters exhibit (Topeka Zoo).

provide an unique outlook that may inspire others to think not only boldly, but differently in their search for creating imaginative, stimulating and rational animal exhibits.

\section{THE ZOO AS THEATER}

The zoo and theater share many strikingly similar purposes: they are both organized institutions committed to educating and entertaining the public through a communication form that involves a place, performers, and an audience (Fig. 1). The AAZPA's accreditation program defines a "zoo" as an organized and permanent institution, especially educational or aesthetic in purpose, with professional staff, that owns and utilizes wild animals, cares for them, and exhibits them to the public on a regular schedule.

Although the physical characteristics of a zoo exhibit and theater stage are dissimilar, both communicate important facts and concepts and rely on presentation to provide an enjoyable and memorable experience. The most outstanding similarity of interest to a designer is the creation of the setting for the animals and/or performers. One purpose of the zoological exhibit is to elicit an emotional and intellectual response from the visitor. Similarly, the stage set for a theater performance, as a creation to help fulfill the playwrights intentions, provokes an emotional response from the audience by producing a mood and crystallizing a theme through the uses of shape, 
color, texture, line, and lighting [Parker and Smith, 1979]. These are the same elements of design that the animal exhibit designer employs to convey an conservation issues. The scene/exhibit, as the environment for performance or display, can play a dominant and integral role or merely serve as background for the actors or animals. Its function is to evoke a response through establishing a mood, more felt than seen, such as warm, gloomy, sparkling, mysterious, etc.

Originally, the word scenery referred only to that used on stage and when it became common in everyday usage, it still suggested this origin; the world was thought of as being a theater with man seen as the actor, occupying the center of the stage [Jackson, 1979]. During the early evolutionary stages of the theatre, the influence of the 16th century descriptive geographer on the nature of scenery design was substantial. The geographer provided natural history accounts of places that had been visited by explorers and world travelers. These descriptions glorified a world of beauty and wonder and made visible the relationship between man and natureincluding animals and plants. The early theater served as a three-dimensional art form to convey descriptions of the world that were often very mythical.

Similarly, the zoo exhibit today is used to communicate knowledge of the natural history of a region with a great emphasis on the visual and the spectacular. The nature or design style of a zoo exhibit can depict a particular attitude about the relationships of man, animal, and habitat. One example of the many design styles emphasizes the animal's physical characteristics by displaying it as a dominant object contrasted with a neutral setting (Fig. 2). The design style of the theater scene and animal exhibit is determined by how the designer chooses to use the elements of design. Style represents a synthesis of design elements as governed by the designer's philosophy; the nature of the message, and the place, time, and locale of the performance/exhibit [Pecktal, 1975]. Consequently, the presence of many styles is fundamental, an inherent characteristic of design that needs to be recognized and perpetuated. Scene/exhibit styles are numerous: realism, abstract, sculptural, architectonic, romantic, formalism, impressionism, representational, ornamental, etc. Each style has a legitimate place in the role of communicating and presenting ideas, opinions, and facts to the observers. The growing use of natural history interpreters and docents in zoos-sometimes acting a role dressed in native costume, using cultural props and telling stories about the animals' native country-supports the zoo as theater metaphor.

The world of nature in the early 17 th century was seen essentially as a background for man's activities. Theater scenery was illusionary, supernatural, and monumental, designed to delight and entertain the public through their imaginations [Jackson, 1979]. The delights of the natural world-as expressed in this period's writing, painting, garden design, theater, and even in the display of animals in a garden setting-reflected the public's enjoyment of natural history. An art form that emerged during the late 18th century and influenced zoo design was the creation of massive panoramic paintings that illustrated spectacular landscape scenes, which often included animals. The naturalistic landscape panoramas designed by Hagenbeck and Eggenschwiller in 1907 at the Hagenbeck Zoo created the first illusionary mixedanimal exhibit and became the predecessor for many of today's zoo exhibits. A strong parallel can be drawn between the $360^{\circ}$ panorama paintings of naturalistic landscape that engulfed and thrilled the patron and the current zoo exhibits that immerse the visitor in the animals' natural habitat. This is a major change in attitude reflected in today's animal exhibits based on landscape immersion-where plant, animal, and man are all seen as equal parts of the same environment. 


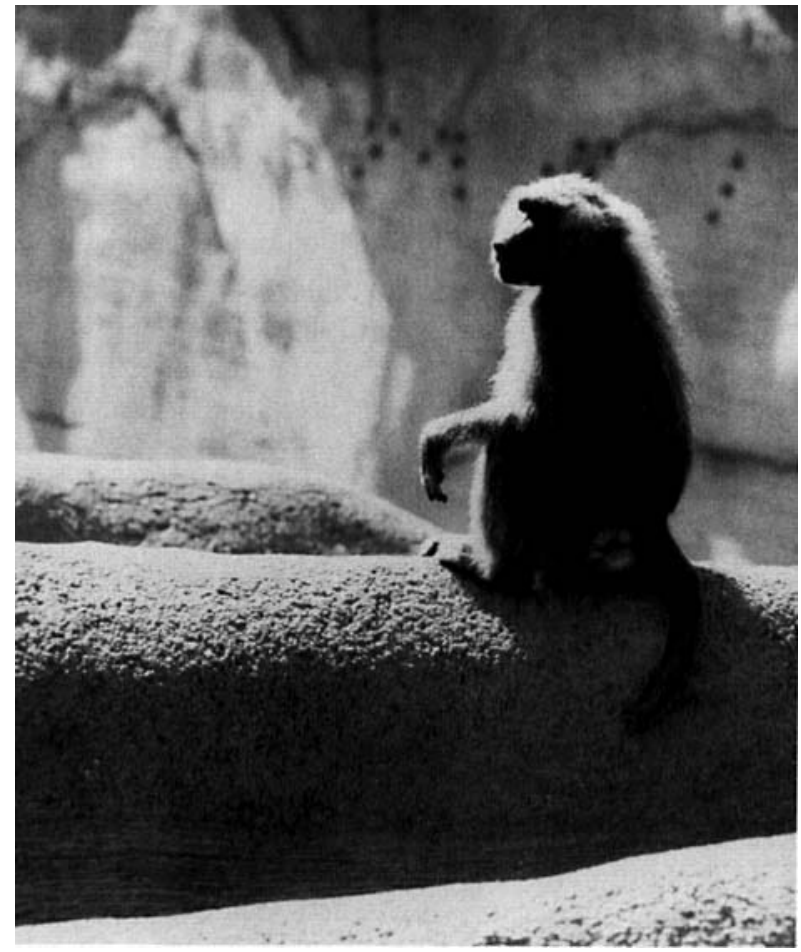

Fig. 2. The neutral and finely textured staged background light contrasts, compliments, and highlights the form and color of the guinea baboon (Brookfield Zoo).

A comparative view of the physical forms currently found in theater and in animal exhibits suggests a similarity in the use of the traditional proscenium theater form. The audience has one dominant view of the stage and/or the caged animal exhibit, while the viewer is placed in a static position. This basic form fulfills many performance and exhibit needs, but new messages awaiting to be conveyed, new concepts of communication, and expanded responsibilities have helped establish new performance and exhibit forms. The "thrust and arena" stage places the audience around the stage, permitting multiple views of the performance (Fig. 3). This is very characteristic of many zoo exhibits where the visitor can select multiple viewing places and observe the animal in a setting with other visitors in the background. The "total environment theater" like the "landscape immersion exhibit" surrounds the audience or visitor with the performers or animals who are always seen in a background void of people (Fig. 4). Technological advances in audio-visual equipment prompted new theater forms such as these and will most likely affect future forms of animal exhibits.

Communication between the exhibited animal and the visitor is often accomplished by staging a story. The storyline (another element of a theater performance) is the connecting thread that holds together other elements, i.e., physical facts on the 


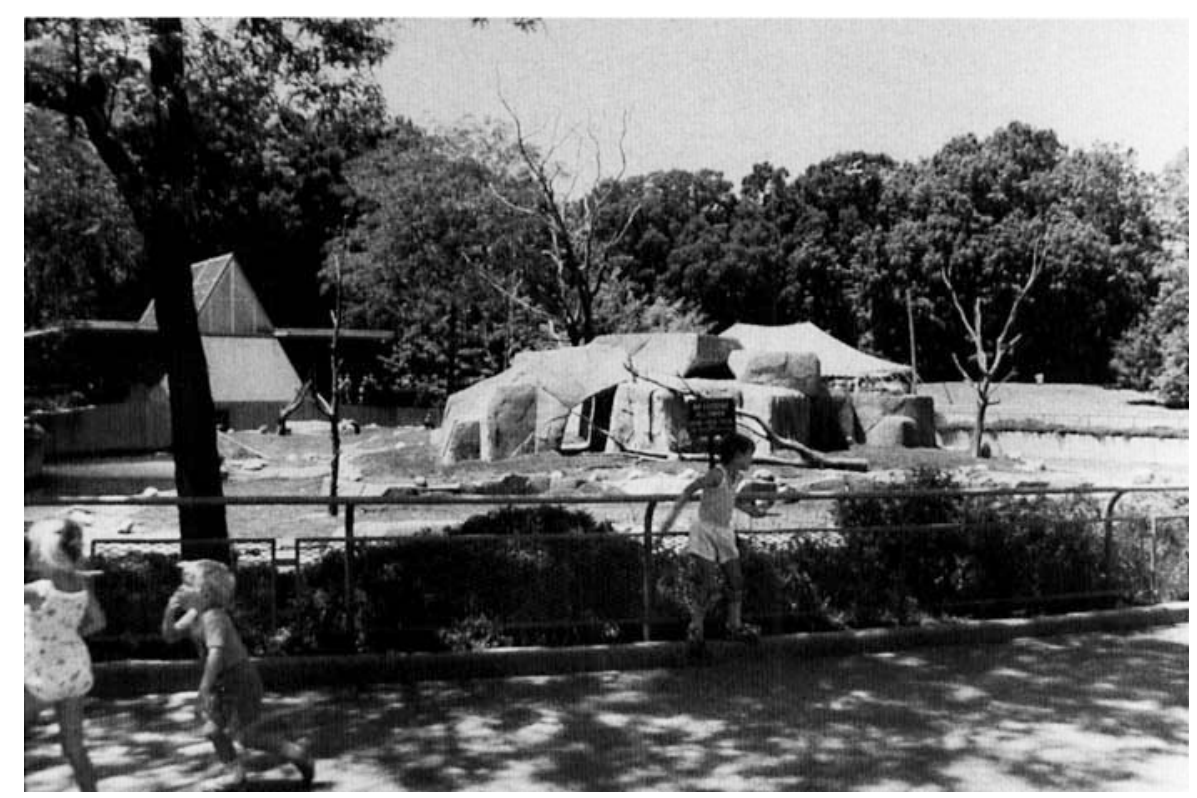

Fig. 3. The "thrust and arena" exhibit provides the observer a variety of views while moving around the perimeter (Milwaukee Zoo).

animal, habitat of the animal, its behavioral characteristics, etc. It is a train of related incidents that brings continuity to the many places and events of the exhibit. The use of a staged story can attract and hold the visitor's attention for an extended period; especially if the exhibit's mood is designed as an integral part of the storyline. The telling of a good story requires a continuous flow of action, information, and interest. The nature of the animal exhibit permits controlled movement of the animal as well as the visitor, providing multiple opportunities, through designed sequence of movement and views, to tell a memorable story.

\section{ILLUSIONS AND EXHIBIT DESIGN}

People visit zoos for many reasons; they come to learn about animals and plants, encounter the unusual and exotic, relax in a pleasant environment, be entertained by the strange and curious behavior of the animals, and become more aware of the relationships between animals, plants, and man. An anticipated visit to the zoo conjures up many joyous and fearful images of what is likely to be encountered. The actual visit is colored by these mental pictures, which are often expanded, realized, and verified because the animal exhibits have an illusionary character. The actual visit to the zoo is often extended and recreated through the retention of images that provoke further illusions of wonder, sadness, and joy.

The zoo is primarily a place to display animals for man's understanding, education, and enjoyment. The zoo exhibit, like the theater, is concerned with creating 


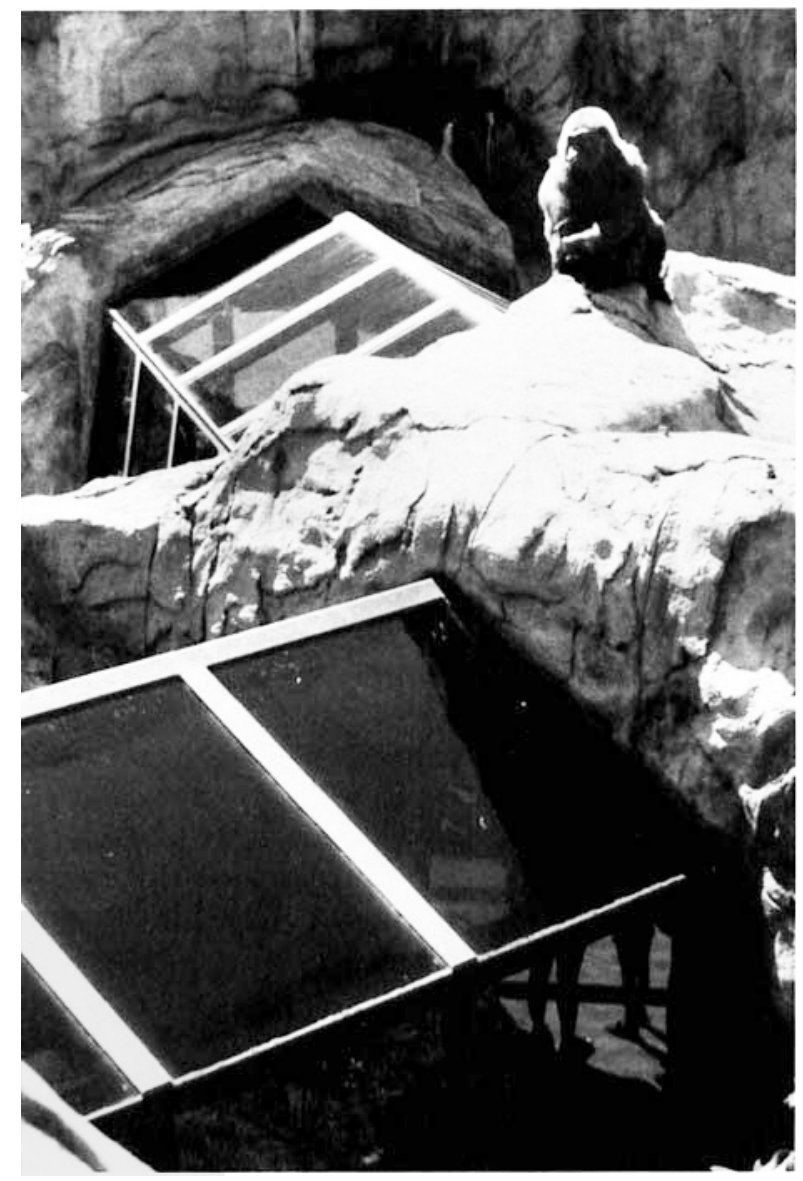

Fig. 4. The "total environment theater" exhibit immerses the zoo visitor in the environment of the animal. It reverses the position of the captive animal and the observer (Topeka Zoo).

illusions to carry a particular message or attitude. Its success is dependent on the images and messages it conveys to the visitor. The art and science of exhibit design relies on illusions to attract the visitors attention, instill a memorable impression, promote an enjoyable experience, and convey a clear educational message.

This perceptual experience is dependent on external forces (the physical features of the exhibit) and internal forces influenced by the visitors past experiences, associations, desires, and demands. Physiological and psychological characteristics of the observer help create illusions that are systematic and measurable, not mere random variations of the nervous system. The exhibit designer, although not in control of the visitors internal forces, which form mental images of the exhibit, manipulates the external forces which include the exhibit forms, sizes, colors and textures. The mind, having the capacity to arrange and organize these elements of design, allows the 
creative and cognitive participation of the visitor [Kepes, 1951]. The human being is impressed with things as they are perceived, not necessarily with things as they are. The chimpanzee exhibit at the North Carolina Zoo offers perceptual clues that provide the observer with the opportunity to create and complete illusionary images. This exhibit uses the site's mature, mixed deciduous and coniferous temperate forest; with its high canopy, deep shadows, and luxuriant green understory, to create a visual illusion of a botanically different tropical forest: the native home of the chimpanzee.

The designer should not be too concerned about clearly understanding the distinction between reality and illusion, which involves the blurred interface of the conscious and subconscious regions of the mind. Illusions are closely linked to emotions and to the lower levels of the psyche that harbor imagination, intuition, and dreams. Illusions can be catalysts for the creation of superb designs. We should admit to the existence of illusions, enjoy the visual puns the mind and eye create, understand their value, and consider their role and application in the design of a zoological exhibit.

The exclamation of dismay, "you have destroyed my illusion," suggests that we not only cherish an illusion, that we hope to gain important enlightment from being its victim. Illusions, sometimes called errors of the senses and/or errors of the intellect, aid in the discovery of reality; helping us to understand the normal and natural. They not only create a sense of enjoyment and attraction, but they can help sustain our search for knowledge and the key to reality. Perhaps all creative thought, in both science and art, has its origins in the sources of illusion. Delacroix has stated that "those things which are most real are the illusions I create in my painting" [Gregory and Gombrick, 1973]. This statement can serve as an appropriate guide for the designer to use while considering the use of perceptual illusions and formulating an approach to exhibit design.

\section{THE USE OF PERCEPTUAL ILLUSIONS IN EXHIBIT DESIGN}

Illusions can be created in animal exhibits to help 1) simulate the animals' natural habitat, 2) produce an atmosphere similar to the animals' environment, 3) focus on the animal's outstanding physical features, and 4) emphasize the ecological relationships between animals, plants, and man. These illusions, assisted by interpretive messages through the use of storytelling, demonstrations, audio-visual performances, and signage, can help educate the zoo visitor about the reality of the animal's natural habitat, biological and ecological principles, the impacts of man on plants and animals, and predator-prey relationships.

Optical illusions in painting, sculpture, theater scenery, garden design, and architecture have occurred for many years with some of the earliest investigations beginning in the mid-nineteenth century. Hypotheses pertaining to illusions are generally lacking in agreement. However, when considering "geometrical-optical" illusions, the two different theories of Lipps and Wundt are conspicuous [Luckiesh, 1965]; most theories of illusion are variants of the following explanations.

1. Lipps' principle of mechanical-esthetic unity states that we unconsciously give to every space-form a living personality and consider the spatial forces created by the forms (line, mass, color) to be real and dynamic. Example: A circular exhibit space has a centripetal character. The spatial radial forces that are directed toward the center are perceptually dominant and overcome the tangential forces that have 


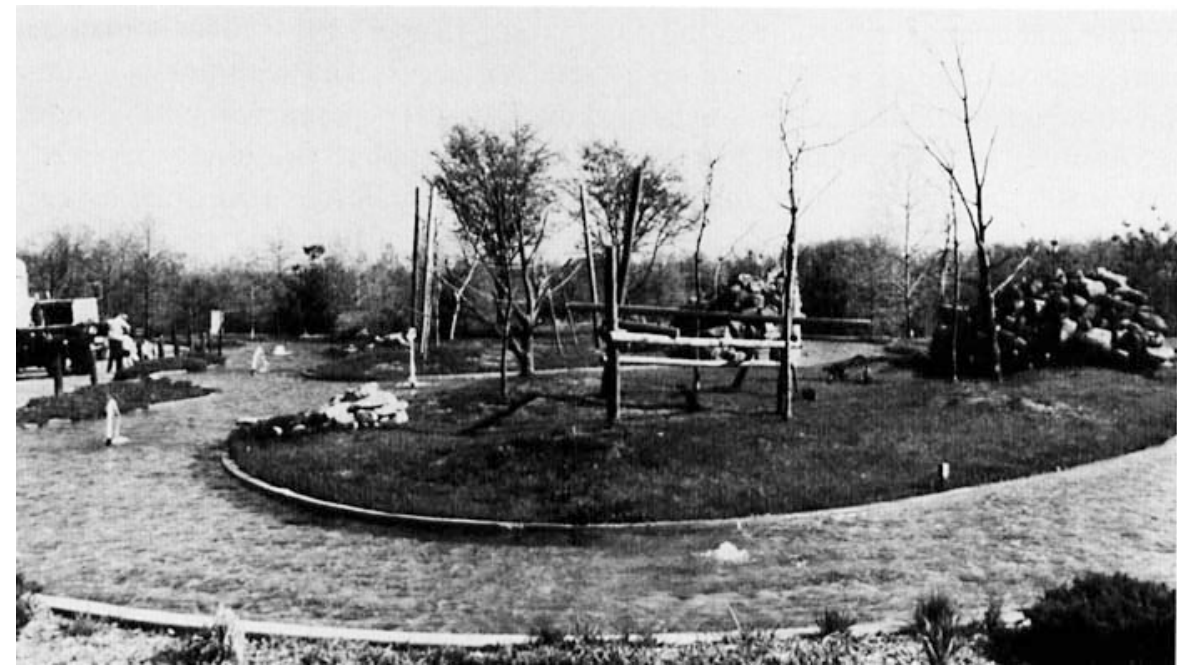

Fig. 5. The circular form of the exhibit, highlighted by the surrounding water and peripheral vegetation, focuses the visitors attention on the central open area; this presents a sense of "closeness" with the animals (Kansas City Zoo).

created the circumference or edge of the exhibit. Consequently, attention is drawn to the center of the exhibit and the apparent size is reduced (Fig. 5).

2. Wundt states that the laws of retinal image (fixation) and eye movement are responsible for illusions and are not due to deception or error judgement. Example: Vertical distances appear greater than horizontal ones because the energy expended raising the eye is greater than that used turning them through an equal angle in a horizontal plane [Luckiesh, 1965].

Optical illusions are provoked by a combination and arrangement of physical design elements employed in all the visual and spatial arts (i.e., line, direction, form, space, size, color, value, and texture). The elements of design and illusion are represented in the animal exhibit by land form, vegetation, water, animals, structures, and elements of the natural atmosphere (sunshine, rain, etc.). A conscious understanding, interpretation, and translation of various types of optical illusions, usually identified with geometry and two-dimensional art forms, may be beneficial to exhibit designers. Knowledge of the different types of illusions may help create imaginative exhibits and may also help the designer avoid the creation of illusions that cancel each other out. Some types of geometrical optical illusions that can serve as design guidelines are:

1. The Effects of the Location in the Visual Field: The size of an object appears larger when it is in a vertical rather than a horizontal position. Example: A log lying on the ground appears shorter than the same size tree standing.

2. Illusions of Interrupted Extent: The distance (depth) and size of an area will apparently vary in extent depending on how the area is treated. Example: A square-shaped area with lines created by walls or plants that run parallel to the viewer will appear smaller than lines running perpendicular to the viewer.

3. Illusions of Contour: The size of an area with well-differentiated borders will appear bigger than an area with loosely defined edges. Example: A circular area 


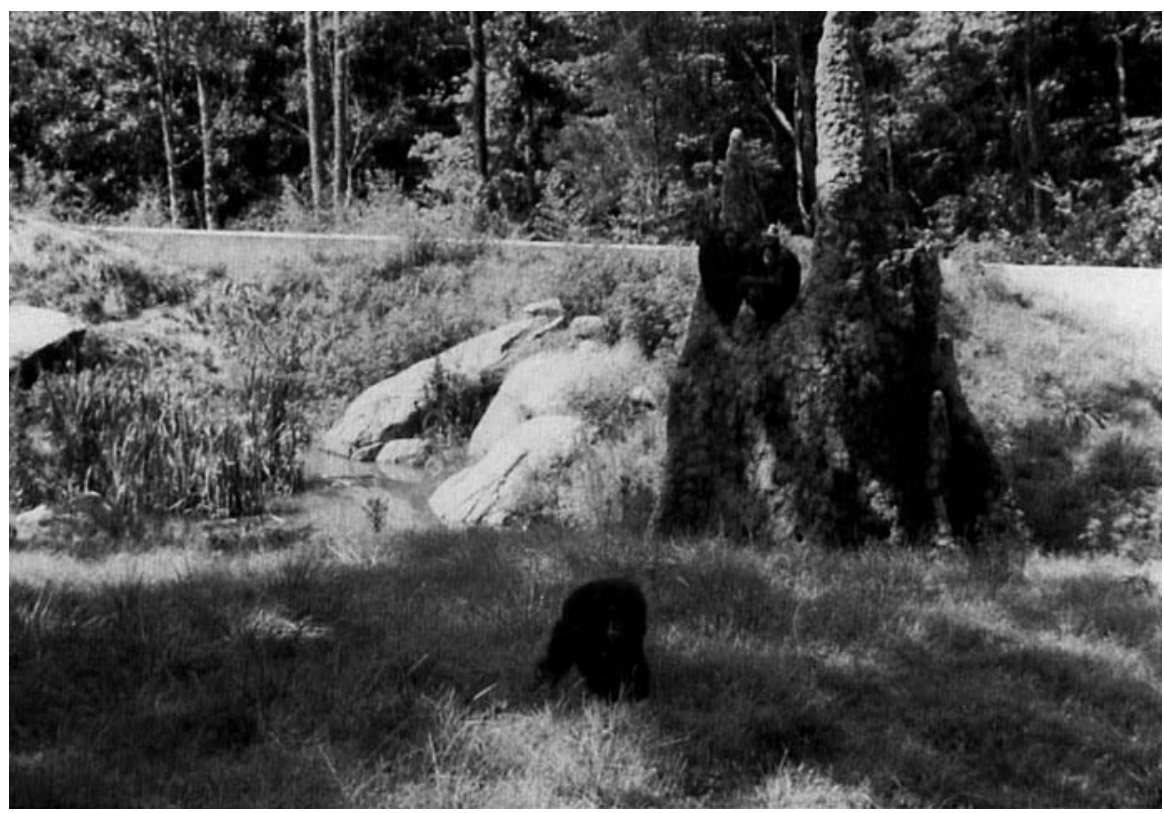

Fig. 6. The apparent depth of this simulated natural landscape is enlarged by different and overlapping site areas and a loosely defined exhibit border (North Carolina Zoo).

with an open segment will appear bigger than the same sized circular area that has the segment enclosed.

4. Illusions of Contrast: Features that are adjacent to large extents appear smaller and those adjacent to small extents appear larger. Example: A tree or rock outcropping within an exhibit that has extended off-exhibit views, will appear smaller than in an exhibit without extended off-exhibit views.

5. Illusions of Perspective: As the complexity of the scene is increased through additional lines, angles, contour, and contrasts, the number of possible illusions is multiplied. Example: An exhibit with many angles, a variety of forms, and large contrasts between the size of parts will appear cluttered and small; sometimes conflicting or unstable illusions will result.

6. Illusions of Depth and Distance: An object will appear more distant in an environment containing a high concentration of dust particles or moisture. An increase in brightness will bring the object closer to the observer. Example: Distance in a clear atmosphere will appear shorter than the same distance in a gray or blushish atmosphere. The background of the North Carolina Zoo in the Smokey Mountains exaggerates the size of the exhibit.

An overlap of forms created by walls, earthworks and vegetation will create a sense of depth. It will also create a feeling of mystery and curiosity because the viewer cannot see the area created between the forms. The attention of the viewer is directed into the middle and background plane. The simulation of transparency and the emphasis of different sized objects from foreground to background can help create illusions of depth and distance (Fig. 6). 
7. Illusions of Brightness Contrast: In general, a dark line or area will appear darker as the brightness of the environment is increased, or conversely, a light spot surrounded by a dark environment will appear brighter as the latter is darkened. Example: An exhibit area with the foreground of the view in the shade will make the middleground or background objects appear much brighter. If the foreground is in the open and fully lit the middleground and background objects can become quite obscure to the observer.

8. Illusions of Simultaneous Contrast in Color: The vividness of a color is dependent on the brightness of color in its surroundings. The apparent change of color to its, complementary can be accomplished by altering its environment. Example: An orange bird seen amid luxuriant green foliage will appear decidedly brighter than when viewed in a grayish or neutral background. As the intensity of light increases, colors will appear less saturated.

9. Illusions of Retiring and Advancing Colors: Colors whose dominant hues are of shorter wave lengths (blue, green) are retiring and those with longer wavelengths (yellow, red) are advancing. The cool or retiring hues can help produce a psychological effect of tranquillity, while the warm color can produce a feeling of excitement and joy.

Lighting, or the design element of value, is a major factor in the creation of a successful exhibit; it provides visibility, reveals form and texture, creates compositions, and provokes an overall atmosphere or mood. Strong backlighting will emphasize the silhouette of a form, while side lighting will strengthen the form's contour. A designer can completely control the amount and quality of light for interior exhibits. Exterior exhibits are totally dependent on the sun as the natural light source during daylight hours. However, the designer has substantial control on the effect of the natural light through the orientation of the exhibit, especially when considering the most popular viewing times. The objects that help create the enclosing vertical, horizontal, and overhead planes should be chosen in according to their light reflection, absorption, and transmission quality. Consequently, the intensity and distribution of light can be highly manipulated. Artificial light sources that augment natural light need additional creative investigation, they could highlight a particular mood desired by the exhibit designer. Concepts and techniques on artificial light sources, night lighting, and lighting programming need further research.

The use of perceptual illusions in the creation of imaginative animal exhibits should be considered as a means for the zoo visitor to discover reality. There may be a conflict between the entertainment and education roles of the zoo because the visitors are often exposed to the stark reality of the natural world when they have come to the zoo to fantasize, day dream, enjoy themselves, and just have fun. The zoo, like the theater, helps conjure up images of fantasy and fiction. It is an unnatural and unreal place that has the ability to attract millions of people.

The zoo may be the best place to educate the public regarding conservation of the worlds' flora and fauna because live animals attract their attention and put them in a mood to learn. Many visitors are at the zoo because of a strong interest in captive or wild animals. This may reflect an attempt to associate with their coinhabitants of the past. Such an attitude can be exploited to teach man about animals and himself. The zoo has the potential for changing public attitudes concerning the conservation of our natural environment by providing a glimpse, although somewhat distorted, of its 
wonder, beauty, and mystery. The fact that some of man's enjoyment and development is based on illusion should be a primary consideration in the formulation of a design approach to animal exhibits.

\section{REFERENCES}

Fossey D. GORILLAS IN THE MIST. Boston Houghton Mifflin Co., 1983.

Gregory, R.L.; Gombrick, E.H. ILLUSIONS IN ART AND NATURE. New York, Charles Scribner's Sons, 1973.

Jackson, J.B. Landscape as Theater. LANDSCAPE 23:3-7, 1979.

Jones, G.R. What is a Zoo? Unpublished manuscript, The University of Michigan, 1985.

Kepes, G. LANGUAGE OF VISION. New York, Theobald, 1951.

Luckiesh, M. VISUAL ILLUSIONS: THEIR CAUSES, CHARACTERISTICS AND APPLICATIONS. New York Dover Publications, 1965.

Parker, W.O.; Smith H.K. SCENE DESIGN AND
STAGE LIGHTING. New York Holt, Rinehart and Winston, 1979.

Pecktal, L. DESIGNING AND PAINTING FOR THE THEATRE. New York, Holt, Rinehart and Winston, 1975.

Schaller, G.B., THE MOUNTAIN GORILLA: ECOLOGY AND BEHAVIOR. Chicago, University of Chicago Press, 1963.

Van Lawick-Goodall, J. MY FRIENDS THE WILD CHIMPANZEES. Washington, DC, National Geographic Society, 1967.

World Wildlife Fund, CONSERVATION YEARBOOK 1985/86, Geneva, WWF-International, 1986. 